\title{
Editorial
}

\section{Deficiencia en sociedad}

Entre otras novedades, la década de los noventa enfatiza la importancia de la sociedad en contraposición al ejército, los políticos y los funcionarios públicos. Para subrayar su importancia ante los otros componentes de la realidad social, se ha vuelto costumbre agregar el adjetivo "civil", en referencia directa al ciudadano común y corriente. Pero al finalizar la década, se constata que, no obstante la insistencia en la importancia de la participación ciudadana en la vida nacional, la democracia salvadoreña presenta un déficit importante en este capítulo, en el que tanto se ha insistido.

Ante esta constatación caben dos preguntas, ¿por qué, pese a la insistencia en su relevancia para la democratización, la sociedad no participa en la toma de decisiones sobre su propio futuro? y, ¿qué habría que hacer para que la población forme parte de los procesos de decisión?

\section{La indiferencia de la sociedad}

La participación ciudadana directa es reclamada como uno de los ingredientes fundamentales de la democracia de fin de siglo. Concurrir a las urnas en los plazos establecidos por la ley para elegir a los funcionarios públicos ya no se considera suficiente para garantizar la democracia, sino que además ahora se exige la intervención directa de la población en la toma de las decisiones importantes para el país. De esta manera, el quehacer político ya no sería un asunto exclusivo de los profesionales de esa actividad, sino que también lo sería de la ciudadanía común y corriente. Las altas esferas del poder nacional e internacional son las que más insisten en la inclusión de la ciudadanía en la gestión de los asuntos públicos. Aparentemente, esto responde a un convencimiento genuino de su necesidad, en orden a profundizar y consolidar la democratización.

Es muy cuestionable, sin embargo, que el poder real -el sector bancario y financiero, vinculado estrechamente al capital internacional, y la clase 
política que le sirve- esté convencido de la necesidad y las bondades de una participación amplia y abierta. Es muy difícil conciliar una participación ciudadana directa y determinante con la naturaleza de ese poder. El crecimiento pasmoso del sector financiero salvadoreño con la subsiguiente acumulación de riqueza es movido por una dinámica concentradora opuesta a la apertura que la participación implica. Su tendencia a anular la competencia es contraria a cualquier forma de participación ciudadana. De la misma forma, ésta tiene muy poco espacio en la política gubernamental y prácricamente ninguno en la económica, donde, por otro lado, más debiera incidir, porque es la que más la afecta.

La democratización de la sociedad y la participación ciudadana en particular no consrituyen el punto fuerte del régimen neoliberal. Promover la participación sin alterar sus fundamentos sólo sirvé para enmascarar y legitimar la creciente desigualdad socioeconómica. En estas condiciones, la participación nunca podrá ser genuina y autónoma, sino que el poder la controlará muy de cerca para evitar intentos orientados a modificar el orden establecido. En el mejor de los casos, el poder concede ciertos espacios, siempre y cuando desde ellos no se cuestionen los principios del régimen neoliberal. Pero aún así, en la medida en que la concentración de la riqueza y, en consecuencia, del poder se incrementen, por un lado, y por el otro, el desempleo, la inseguridad y la falta de oportunidades, y con ellos el malestar social, ese espacio tiende a cerrarse para impedir que las contradicciones del régimen salgan a la luz pública. Este se esfuerza sobremanera para proyectar una imagen de normalidad y así mantener la expectativa de un futuro próspero.

No obstante lo anterior, el orden neoliberal necesita con urgencia una legitimación social que vaya más allá de los eventos electorales periódicos. Por eso invita con insistencia a la población a participar. Pero hasta ahora, ésta no se ha mostrado muy interesada. Su desinterés en la actividad política es evidente incluso en las elecciones mismas. Las encuestas electorales muestran una abstención creciente, con lo cual los funcionarios electos tienen cada vez menos representatividad, puesto que cada vez son elegidos por menos ciudadanos. De igual forma, las encuestas de opinión pública reflejan de forma sistemática la indiferencia de la población ante las grandes decisiones políticas y sociales, pero sin que esto signifique que no tenga un juicio de valor sobre ellas o su situación. Pareciera que la población, enseñada quizás por una década neoliberal de promesas incumplidas y frustraciones acumuladas, sabe de alguna manera que el régimen actual no la librará del desempleo y de la inseguridad ni le proporcionará la oportunidad para superarlas.

\section{Una alternativa: la participación desde abajo}

La alternativa que ofrece el poder no es la única, aunque hay que tomarle la palabra y esforzarse por participar en el proceso donde se toman las 


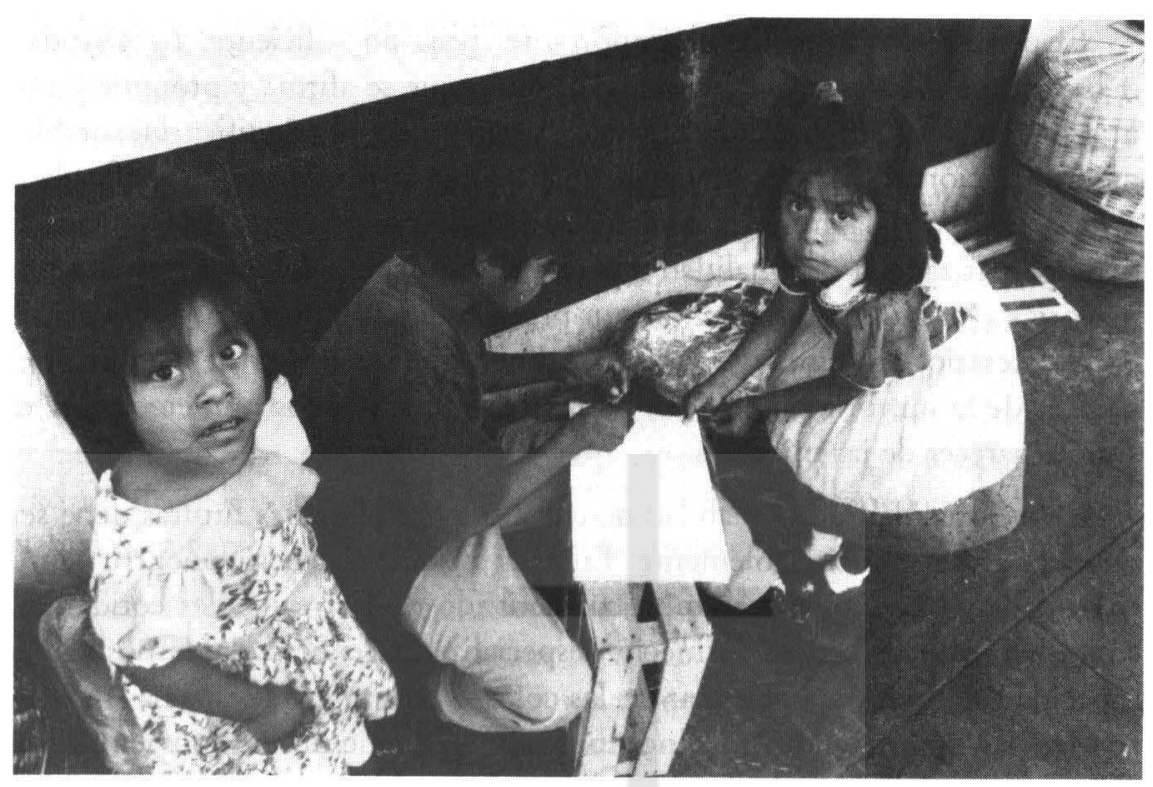

decisiones nacionales. Pero la razón última de esta participación no debiera ser la apertura de un espacio, lo cual, sin duda, ayuda; sino el ejercicio de un derecho y una obligación, porque si aquél fuera negado o sólo es concedido de forma limitada, es necesario reclamarlo. La apertura del espacio para la participación, en sí misma, es ventajosa y no debiera desaprovecharse. Sin embargo, el derecho a participar debe ser conquistado por la sociedad misma. Sólo así el ofrecimiento desde el poder podrá convertirse en una participación real y transformadora de la realidad salvadoreña actual.

La sociedad debe asumir plena y conscientemente su derecho $-\mathrm{y}$ también su obligación- a decir su propia palabra sobre su realidad presente, futura e incluso pasada. Ni los políticos ni mucho menos el ejército pueden censurar los temas y los tiempos sobre los cuales la sociedad deba hablar o debatir. Ahora bien, no se trata únicamente de hacerse oír, sino que la palabra dicha por la mayoría de la población sea eficaz, para lo cual debe convertirse en acción configuradora de la realidad. Esta palabra desde abajo no sólo es eficaz por provenir de la mayoría de la población, sino sobre todo por la capacidad transformadora que pueda poseer. Para transformar, la palabra debe volverse principio de acción, creando realidades sociales y personales nuevas.

La democratización de la sociedad y la participación ciudadana en particular no constituyen el punto fuerte del régimen neoliberal. 
El peso de los números es importante, pero no suficiente. La cantidad debe ser cualificada por la racionalidad de lo que se afirma y propone y por una buena dosis de viabilidad. Mayoría o popular no significa inexorablemente irracionalidad. Por lo tanto, su palabra no puede ser descalificada $a$ priori. Tampoco la minoría que suele decidir por el resto de la sociedad tiene garantizada la racionalidad a priori, sino que ésta debe ser buscada por mayorías y minorías por igual, en un proceso difícil y no pocas veces árido, pero necesario. Sin embargo, en un régimen que quiera ser democrático, el parecer de la mayoría posee de antemano la ventaja de los números sobre el simple parecer de las minorías.

La racionalidad de la realidad actual y sus posibilidades futuras debe ser buscada ardua e incansablemente. En esta búsqueda deben concurrir tanto la ciudadanía con su saber empírico, derivado de las realidades coridianas, como los técnicos con su formación especializada. La ciudadanía posee una capacidad natural para penetrar en las cosas y las situaciones más allá de las apariencias, imprescindible cuando busca aquello que más le conviene. Con todo, sus intuiciones y hallazgos deben ser respaldados por la racionalidad aportada desde el saber científico y tecnológico. Esta coincidencia de saberes es posible cuando ambas búsquedas se encuentran animadas por el deseo genuino de dar con el bien de todos.

Además de intensa y constante, la búsqueda del bien común debe caracterizarse por una actitud beligerante, puesto que para avanzar tendrá que hacer contra la ignorancia y la mentira, por medio de las cuales se anteponen los intereses particulares al interés general, presentándolos además como el bien general. Dado que la ignorancia y la mentira suelen ir acompañadas de la injusticia, esa beligerancia tiene que ser mayor. La sociedad no puede permitir que su propia verdad sea aprisionada por la injusticia y la mentira. De ahí que, el conflicto entre quienes buscan la verdad de la realidad social y quienes prefieren ignorarla u ocultarla para escabullir su compromiso o conservar sus privilegios, sea inevitable.

El consenso, un bien muy elogiado por la actualidad neoliberal, si no está precedido por un debate en el cual aparezcan los intereses y las ideologías encontrados, puede convertirse en una mentira más para mantener la apariencia de armonía social, ocultando el conflicto sobre el cual descansa la estructura social. El consenso no debe ser usado para mantener apariencias que, por orro lado, periódicamente son puestas en evidencia por brotes de conflictividad social inevitables y a veces inesperados; sino que debe ser comprendido como un medio eficaz para administrar racionalmente dicha conflictividad. Dadas las circunstancias, el consenso es necesario, pero su solidez depende de la confrontación previa de intereses e ideologías contradictorios.

La sociedad no puede renunciar a tener opinión pública ni a expresarla y 
defenderla. Pero debe ser consciente de que no por eso le está garantizada la racionalidad necesaria para ordenar la convivencia social. Es un elemento fundamental de la búsqueda del bien común, pero no es el único. La formación, la información, la reflexión y la organización constituyen también elementos claves de esta búsqueda. Si fallan, la opinión pública puede caer en la irrelevancia por ineficaz e inviable o ser más vulnerable a la manipulación por parte de intereses espúreos $\mathrm{y}$, por lo tanto, a caer con mayor facilidad en las trampas de la falsa democratización, en cuanto no responda a las aspiraciones y necesidades de las mayorías populares. No se trata, por lo tanto, de hablar por hablar desde la perspectiva de las grandes mayorías, sino de decir la verdad sobre su realidad coridiana y proponer soluciones viables para garantizar la satisfacción de sus necesidades básicas.

Nunca se insistirá lo suficiente en que la fuerza de la participación ciudadana radica en la racionalidad de sus posturas. Al originarse en las bases de la sociedad y estar animada de alguna manera por la búsqueda del bien común, esta participación es más proclive a encontrar soluciones verdaderas a la problemática nacional que los políicicos y gobernantes, por lo general motivados por otra clase de intereses. Con más frecuencia de lo que parece, el saber popular tiene más sentido común que el de los políticos y funcionarios. Debidamente formado, informado y organizado, ese saber puede verse potenciado, convirtiéndose en una fuerza transformadora muy importante. En cualquier caso, esta actitud de búsqueda incesante y comprometida con la verdad, la razón y el bien evita los peligros de la demagogia y del populismo, tan comunes en la participación popular.

En la actualidad, el contenido de la búsqueda del bien de la sociedad debiera estar determinado por dos principios, uno de orden filosófico y el otro económico: el destino universal de los bienes materiales y el conflicto de intereses. Del destino universal de los bienes materiales se deriva el derecho inalienable de los individuos a gozar de un mínimo de bienestar, es decir, sus necesidades básicas (empleo, salud, educación y vivienda) deben estar sarisfechas sin menoscabo de las generaciones fururas. Dado que el mercado no garantiza este mínimo, la sociedad está obligada a

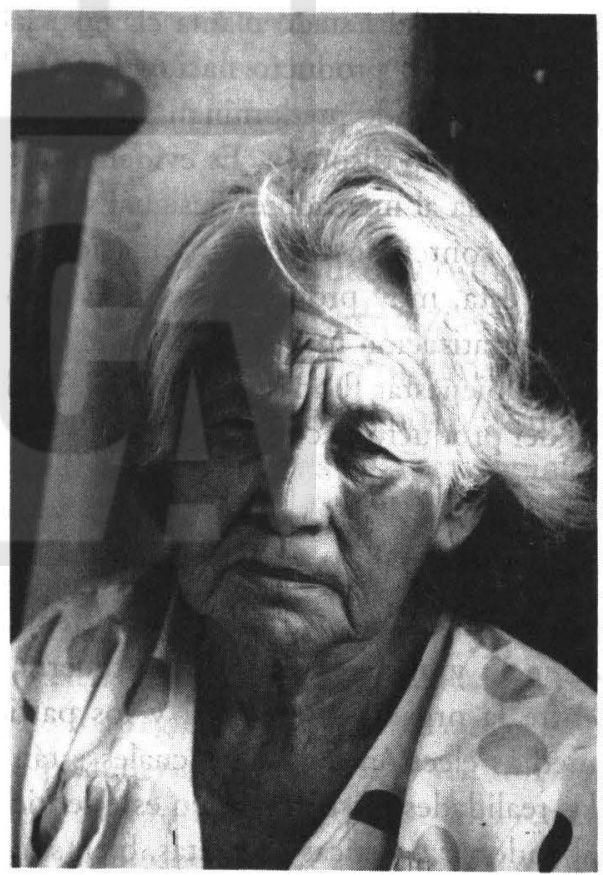


hacer que los bienes materiales cumplan con su destino universal de satisfacer las necesidades básicas de todos sus miembros así como también de todos los integrantes de todas las sociedades del planeta. De esta forma, la sociedad - nacional, regional o mundial - se convierte en la última responsable y garante del desarrollo general y del bienestar de todos.

Económicamente, el comportamiento de los individuos en el mercado lleva necesariamente al conflicto de intereses, el cual sólo puede ser resuelto o moderado por una instancia exterior a aquél, en este caso, por la sociedad, pero también por el Estado —o incluso por una clase social. De ahí la necesidad de insistir en la redistribución de los frutos del trabajo, del capital, de la tierra y de otros recursos naturales de una manera más coherente con el destino universal de los bienes. La redistribución que el régimen neoliberal relega al final del proceso de crecimiento, haciendo de ella una especie de "redistribución escatológica" (Luis de Sebastián), debe convertirse en la fuerza movilizadora contra el primero. El supuesto proceso por medio del cual lo que sobra a los niveles superiores llega a los inferiores no es viable ni aceptable éticamente.

La sociedad debe asumir plena y conscientemente su derecho

-y también su obligación-a decir su propia palabra sobre su realidad presente, futura e incluso pasada.

La sociedad, por consiguiente, tiene que intervenir de alguna manera por medio del Estado o una clase social- para garantizar la redistribución equitativa del producto nacional y moderar los conflictos generados por el mercado, donde predominan las relaciones de fuerza entre los diversos grupos que se lo disputan. Es evidente que la distribución del producto nacional dejada al mercado es désigual y, por lo general, injusta. En la medida en que el contenido de la participación sea determinado por estos dos principios, ésta, muy probablemente, se profundizará e intensificará, haciendo la democratización más real. ¿De qué otra cosa debe tratar la democracia si no es del bienestar fundamental de los ciudadanos y de la distribución equitativa del producto nacional?

\section{Desafíos para la participación}

La participación ciudadana enfrenta al menos cuatro desafíos - la indiferencia y el desengaño de postguerra, la derivación de poder, la relación entre la organización social y los partidos políticos, y la influencia de los medios electrónicos-, los cuales están determinados, en gran medida, por las realidades existentes y, en este sentido, representan una oportunidad para abandonar prácticas obsoletas, bien sea por agotamiento de sus posibilidades 
- por su carácter abiertamente antidemocrático. Sin embargo, la superación misma de estos desaflos tiene su propia complejidad, porque no está exenta de peligros que deben ser evitados.

El primer desafío lo constituyen la indiferencia y el desencanto de postguerra. El balance final de la guerra al no arrojar un saldo posirivo en cuanto a la mejora de las condiciones de vida de la mayoría de la población, en parte porque no era el medio idóneo, y en parte porque los negociadores de su conclusión renunciaron a tratar el tema, inyectaron una fuerte dosis de indiferencia en la sociedad salvadoreña. En lugar de

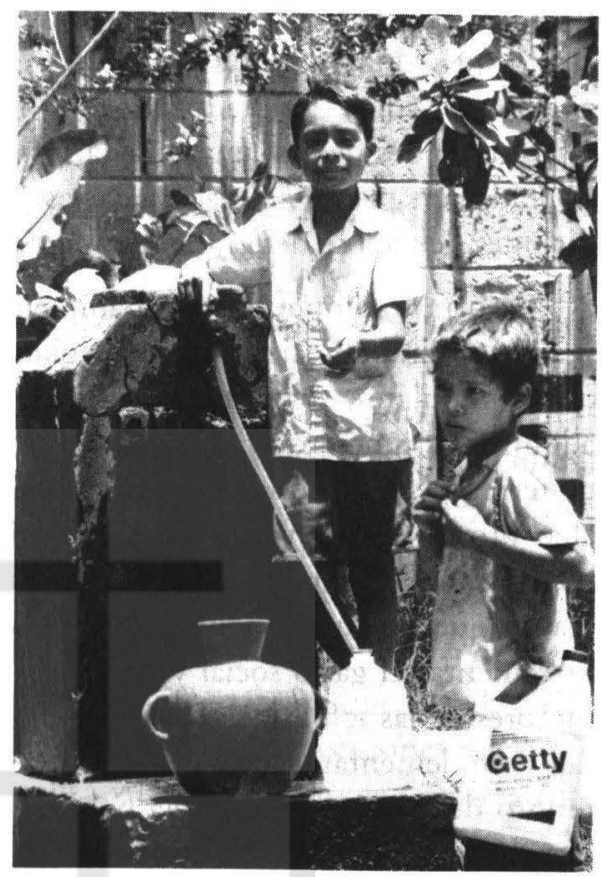
las transformaciones sociales prometidas, llegó la primera ola de reformismo neoliberal. Con ella, los índices sociales retrocedieron a niveles inferiores a los de antes de la guerra y la precariedad de la vida fue reforzada por una violencia generalizada, que en los últimos años ha cobrado más víctimas mortales que el promedio anual de la guerra. La fuerza con la que el régimen neoliberal se impuso dio paso al desencanto. Su aparente inevitabilidad intenta descartar a priori cualquier reconsideración del mismo, inhibiendo simultáneamente el interés en el cambio social.

El consenso, un bien muy elogiado por la actualidad neoliberal, si no está precedido por un debate en el cual aparezcan los intereses y las ideologías encontrados, puede convertirse en una mentira más para mantener la apariencia de armonía social, ocultando el conflicto sobre el cual descansa la estructura social.

Esta actitud no significa, sin embargo, que la población salvadoreña legitime las reformas, sino que no las acepta ni está dispuesta a colaborar con el tipo de democracia que se le está ofreciendo. Este rechazo tampoco puede interpretarse como un voto a favor de los regímenes no democráticos. En teoría, los gobiernos salvadoreños de postguerra impulsaron el reformismo neoliberal como requisito indispensable para fortalecer la democracia recién estrenada y para preparar el camino a la prosperidad. Fueron persuadidos 
para que sacrificaran la producción a la estabilidad monetaria y fiscal, esperando que, una vez estabilizada la economía, el desarrollo se les daría por añadidura, como resultado lógico y necesario del equilibrio macroeconómico. Después de casi una década, la prosperidad no llega aún y en cambio la población pierde empleos, salarios y oportunidades, con lo cual sus condiciones de vida se deterioran de una forma alarmante.

Mientras tanto, el régimen también pierde credibilidad a los ojos de esta población empobrecida y desprotegida. La desaprobación no se limita a las clases populares, sino que se extiende entre las clases medias, cuyo poder adquisitivo también experimenta reducciones drásricas y, junto con él, pierde terreno en el campo de las decisiones políticas importantes. Si no se hace algo pronto para revertir esta tendencia, las reformas y sobre todo los gobiernos que las impulsan acabarán poniendo en peligro la estabilidad democrática que desean salvaguardar. Así es como han surgido las iniciativas para incrementar el gasto social y promover la participación ciudadana. Los promotores de las reformas neoliberales, en concreto el Banco Mundial, quisieran complementarlas con cambios sociales, orientados a contrarrestar el deterioro del nivel de vida de la población salvadoreña. Parte fundamental de este esfuerzo es un acuerdo básico de la sociedad sobre el contenido de dichas reformas y las fuentes de su financiamiento. En este contexto surgió la iniciativa de las Bases para un plan de nación.

Hay que advertir, sin embargo, que no cualquier apertura a favor de la participación de la población en el destino de El Salvador es válida. La consulta popular para formular los fundamentos del plan de nación, impulsada por el gobierno, corre el peligro de fracasar, porque el grupo gestor, responsable de su promoción, no tiene poder de convocatoria y, como si esto fuera poco, carece de credibilidad. Sus integrantes no se han distinguido por su sensibilidad ante cl deterioro de las condiciones de vida de las mayorías populares, ni por su tolerancia ante opiniones contrarias a las suyas, ni por su apertura para discutir una problemática social compleja. Reaccionando a presiones de diverso tipo, el presidente Calderón intentó en vano abrir nuevas posibilidades para dicho grupo, agregando nuevos miembros, en lugar de reestructurarlo completamente de acuerdo con su concepción original.

La proyección simultánea de imágenes contradictorias, un fenómeno típico de la postguerra salvadoreña, contribuye a alimentar la indiferencia de la sociedad. Los mensajes contradictorios que estas imágenes envían a una población indiferente no son los más apropiados para promover una discusión abierta y amplia. Mientras el gobierno asegura sin convencer que El Salvador marcha directo hacia el éxito económico; por otro lado, reconoce, en un documento semioficial, que su problema fundamental es la pobreza estructural. Mientras, por un lado, invita a la ciudadanía a expresarse y 
participar en el debate de los problemas nacionales; por el otro, legisla y gobierna prescindiendo de ella. Prueba palpable de esto es la crisis en que se encuentra el sistema de salud pública, la cual pudo haber sido evitada con una buena dosis de diálogo y negociación. El contraste entre el discurso y la realidad, en una sociedad todavía muy polarizada, aleja aún más a la población de la vida nacional, reforzando su apatía.

De todos modos, independientemente del origen de las iniciativas para poner de acuerdo a las fuerzas sociales sobre los lineamientos fundamentales de un plan de nación, es evidente que El Salvador requiere cambios drásticos y urgentes, los cuales no debieran hacerse sin escuchar a sus habitantes. Pero éstos participarán sólo si están convencidos de su seriedad y de su impacto directo e inmediato sobre su precaria situación. Por lo tanto, la distribución equitativa del producto nacional y del poder deben constituir el meollo de los cambios a impulsar.

El segundo desafío es la delegación de poder intrínseca que la participación conlleva cuando tiene potencial para influir en las decisiones nacionales. En la medida en que la opinión pública y la presencia de la organización social influyan en el rumbo del país, adquirirán poder, profundizando así la democratización de la sociedad y del Estado. Es intrascendente promover la participación ciudadana sin la disposición a delegar poder y aceptar todas las consecuencias transformadoras que dicha delegación comporta. En consecuencia, sin esa delegación de poder real, tanto la participación como la democratización se vuelven formalidades sin contenido.

Incluir a la ciudadanía en la gestión pública implicaría abrir espacios para que pueda expresar libremente sus opiniones y juicios, sus quejas y propuestas, contribuyendo así a determinar la respuesta a los graves problemas nacionales, regionales o locales. Pero esta apertura implica, asimismo, la disposición a escuchar con atención la voz ciudadana y a respetar su voluntad, teniéndolos muy en cuenta en el momento de decidir, tanto que quienes tienen el poder para ello no debieran -a no ser que tengan razones muy poderosas y de mucho peso- tomar decisiones en contra del parecer y querer evidente de la mayoría de la población. Existen mecanismos formales -referéndums, plebiscitos, consultas populares, cabildos abiertos, etc.- e informales —encuestas de opinión, organismos no gubernamentales, espacios de opinión en los medios de comunicación social, manifestaciones públicas y variadas formas de expresión popular- a través de los cuales esa voz y ese querer se manifiestan.

Si esto llegase a ocurrir, el poder, inexorablemente, tendría que ser ejercido de una forma más democrática y, por lo mismo, transformaría de forma radical la estructura de la sociedad. En realidad, éste es uno de los puntos más débiles de la participación. Una cosa es promoverla a nivel de discurso y otra muy distinta es llevarla a la práctica, compartiendo el poder de deci- 
sión con la sociedad y sus organizaciones. No es extraño, entonces, que propuestas como la consulta popular para dilucidar cuestiones relacionadas con el medio ambiente hayan encontrado una resistencia tenaz en los grupos de poder. Por la misma razón, la descentralización del poder central en beneficio de los poderes locales es algo más que transferir fondos y por eso avanza con tanta lentitud. En esta misma línea de resistencia a descentralizar el poder, los partidos políticos se oponen a liberar al sistema electoral de su tutela. El parecer de la población no es escuchado cuando se legisla o cuando se eligen funcionarios como el Procurador para la Defensa de los Derechos Humanos.

En la medida en que la actividad política no esté al servicio del bien común, la participación ciudadana difícilmente encontrará razón y esperanza para superar el desencanto y la indiferencia así como los medios idóneos para desarrollarse y expresarse de forma determinante. La cuestión de fondo estriba en aceptar que el poder reside en el pueblo, el cual lo delega de manera temporal a un partido político o a unos políticos determinados para que administren la cosa pública en bien de todos y no de ciertos grupos. La participación de la ciudadanía en la gestión pública garantizaría mejor que los políticos y funcionarios públicos la consecución del bien común, al mismo tiempo que cuestionaría el destino que en la actualidad se da a los recursos naturales, la acumulación y concentración de la riqueza nacional y los procedimientos por los cuales ello es posible. Pero para que la participación gane el espacio que el discurso polírico le concede es necesario redistribuir la riqueza y el poder de una forma más equitativa así como también eliminar todos los privilegios.

El tercer desafío importante para la participación ciudadana proviene de su relación con los partidos políticos. Estos últimos han demostrado sobradamente su incapacidad o desinterés para ocuparse de las cuestiones que más preocupan a la sociedad. En consecuencia, ya no canalizan —si es que alguna vez lo llegaron a hacer- - las demandas de la sociedad, el control que pueden ejercer sobre ella es muy limitado y tampoco cumplen con su papel de intermediación entre ésta y el Estado. En la actualidad, los partidos políticos han quedado reducidos a meras maquinarias electorales, que movilizan a sus simpatizantes únicamente de cara a las elecciones. Es así como se explican la desconfianza y el descrédito en que han caído ante la ciudadanía, a lo cual contribuyen, en no poca medida, los escándalos periódicos.

No obstante el alejamiento de la sociedad y sus problemas y el consiguiente desprestigio de los partidos políticos, la sociedad, por muy organizada que se considere, no puede aspirar a reemplazarlos. Los partidos políticos tienen una función importante e insustituible dentro de la estructura social, por lo tanto, hay que forzarlos a cumplirla. La presión que la organización social pueda ejercer en este sentido no debe llevar a pensar erróneamente 
que la sustitución es posible.

Los partidos políticos tampoco deben caer en el error contrario, pensar que pueden representar cabalmente los intereses de la sociedad, sobre todo cuando ésta se encuentra conformada por un mosaico de grupos e incluso de subculturas muy definidas. Los políticos deben aprender a respetar la autonomía de la sociedad y sus organizaciones asi como acostumbrarse a tratar con todas ellas, intentando responder a sus expectativas. Este aprendizaje toma tiempo y requiere de mucha apertura y madurez, sobre todo porque la práctica política tradicional atribuye a sus agentes un saber y un poder cuasi absolutos. Sin embargo, no hay que pasar por alto que aquí se decide no sólo el futuro de los partidos y los políticos, sino también el de la democracia. En consecuencia, la práctica política predominante debe experimentar cambios drásticos. Los mecanismos de participación representativa tradicionales están agotados, es decir, cada vez representan menos y, en esa medida, se aíslan más de la realidad social. En lugar de sentir nostalgia por el pasado, protestando por las exigencias que las nuevas realidades sociales y la participación directa imponen sobre la actividad política, los políticos deben hacerse cargo de las transformaciones del mundo actual e intentar influenciarlo.

Ahora bien, no se puede desconocer que entre los partidos políticos y la organización social existe una atracción muy fuerte. Los partidos políticos necesitan el respaldo de la ciudadanía para conseguir sus objetivos electorales, mientras que ésta a su vez necesita de la aquiescencia de aquéllos para satisfacer sus demandas. El respeto a la identidad y autonomía de cada una de estas fuerzas requiere de equilibrios difíciles, pero no por eso menos necesarios. La atracción mutua, por muy poderosa que sea, no puede arrastrar a la confusión, porque ello desvirtuaría la función social de ambos. La colaboración que pueda haber entre ellos debe respetar siempre la autonomía del otro. Cuando la organización social se pone al servicio de los intereses partidistas de forma exclusiva, pierde su razón de ser, pues es absorbida por la dinámica de aquél, orientada a la consecución del poder estatal. El partido político, precisamente por eso mismo, no tiene capaci-

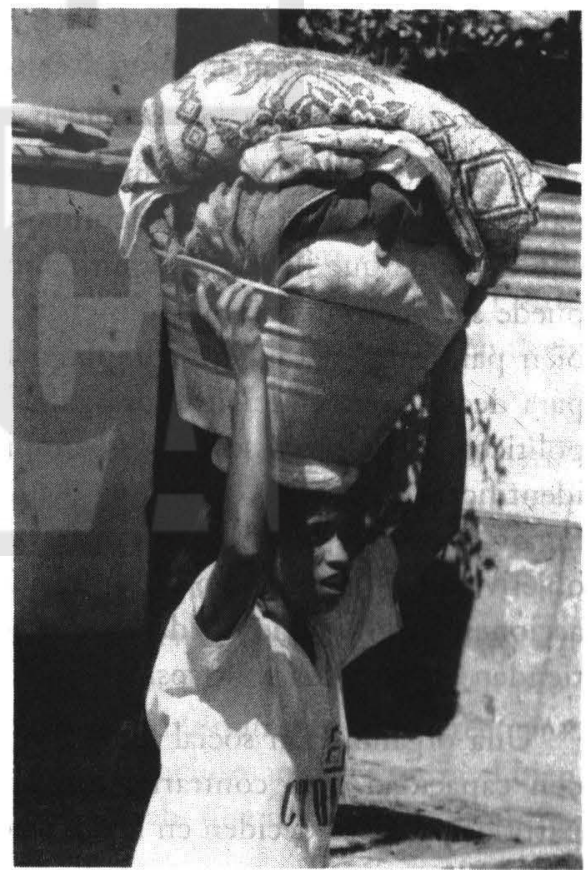


dad para promover y defender los intereses de las organizaciones sociales. En consecuencia, la autonomía de cada uno debiera ser cuidadosamente respetada y defendida, sin menoscabo de posibles colaboraciones o apoyos puntuales.

El déficit que El Salvador actual presenta en participación ciudadana no es fortuito, sino que está relacionado intrínsecamente con la estructura social predominante. En consecuencia, su superación no es cuestión de voluntarismos más o menos bien intencionados, sino de transformaciones estructurales radicales.

Aparentemente, la izquierda estaría más próxima a las demandas populares $\mathrm{y}$, por consiguiente, sería más proclive a promover la participación amplia en la toma de las decisiones nacionales; pero, al igual que la derecha, con relativa facilidad cae en la tentación de usar la organización social como correa de transmisión, mediatizándola e incluso manipulándola, cuando así conviene a sus intereses partidistas. En la medida en que la consecución del poder absolutice la actividad partidaria y los políricos no estén convencidos de las ventajas de la autonomía del movimiento social así como de su capacidad para pensar y proponer, se arrogan una representación que no poseen. Entonces, lo que le conviene al partido también conviene a la sociedad sin solución de continuidad. Naturalmente, en estas circunstancias, lo que los ciudadanos tengan que decir resulta superfluo, porque el partido ya lo sabe de antemano. Estas prácticas tan inveteradas como reñidas con la sana política son contrarias a la participación que se quiere promover como parte esencial de la democratización.

Dados los peligros que enfrenta esta relación, la sociedad debe luchar para preservar siempre su autonomía frente a cualquier partido político. De ello depende que llegue a adquirir una cuota de poder importante, la cual puede ser determinante no sólo en el momento de contar votos, sino también para exigir y aun para imponer las reformas necesarias. Su capacidad para decidir una elección le otorgaría poder para negociar con los partidos políticos el compromiso con los cambios sociales que la favorecen, pero sin identificarse con ellos, relegando a un segundo plano su propia identidad. La organización social debe conservar su independencia para juzgar con objetividad el desempeńo de los políticos y para pedirles cuentas de sus acciones. No hay que olvidar que el lenguaje electoral es el que mejor entienden los partidos políticos.

Una organización social semejante se convertiría en una fuerza política con capacidad para contrarrestar el poder cuasi absoluto con el cual los partidos políticos deciden en la actualidad sobre los asuntos nacionales. Este 
contrapeso es una necesidad, porque el carácter cuasi absoluto de este poder con facilidad se desliza hacia prácticas autoritarias y antidemocráticas. Una organización social fuerte e independiente de los partidos políticos puede convertirse en la fuerza que determine quiénes serán los gobernantes y puede llegar a obligarlos a gobernar de acuerdo al bien común. Esta fuerza podría frenar no sólo las veleidades y arbitrariedades de los políticos, sino que además dotaría de realidad social a su representación política.

En la práctica, sin embargo, esto no es tan sencillo. El movimiento o la organización social no es homogénea. Una de las características de la sociedad de fin de siglo es la existencia de múltiples agrupaciones y organizaciones sociales con identidades e intereses no sólo diferentes, sino también muy particulares y con frecuencia contradictorios, lo cual vuelve muy difícil poder hablar de un movimiento social uniforme. En consecuencia, es función de los partidos políticos y del Estado mismo intentar armonizar esa gama de intereses variada y excluyente sin menoscabo del bien universal. Este intento es más complejo cuando cada uno de estos grupos sólo está interesado en satisfacer sus propias demandas sin importarle cómo ello afecte a los demás o a la sociedad en su conjunto. La fragmentación de la sociedad y el individualismo de las partes que la integran representan una dificultad adicional a la hora de formular un plan de nación.

El cuarto desafío proviene de los medios electrónicos, los cuales facilitan la consulta rápida y masiva. Los medios de comunicación masiva y las encuestas de opinión están sustituyendo las formas tradicionales de contacto entre los políticos y la sociedad. Las nuevas tecnologías están desplazando la reunión, la comisión, la asamblea, el mitín, etc. Es así como el debate nacional ya no tiene lugar en los recintos políticos tradicionales, sino en los medios electrónicos. Si bien esto evidencia, por una parte, la debilidad del sistema político actual, apegado a formas que se desactualizan con una rapidez vertiginosa; por la otra, está exigiendo una transformación radical, no sólo en relación a los medios utilizados, sino en cuanto a la participación misma, puesto que las nuevas recnologías favorecen la participación masiva y directa de la ciudadanía. Desde esta perspectiva, la clase política se está quedando desfasada, lo cual también contribuye a su descrédito - si no a su obsolescencia.

Aunque los medios electrónicos poseen potencial para promover la participación masiva y directa, la sociedad debe estar muy alerta para no dejarse sorprender por quienes los controlan. Las empresas de la comunicación crean, compran, venden, difunden y, en buena medida, imponen los mensajes que configuran la formación de la conciencia política, la educación ciudadana y también sus pasatiempos. Estos mensajes así como pueden promover y cultivar horizontes más humanos, al difundir valores y creencias, también pueden fomentar prejuicios y fobias e incluso atentar contra el bien común y el destino universal de los bienes. De ahí que no sólo la concentra- 
ción del poder económico requiere algún tipo de control social, sino que también el poder sobre las mentes y las conciencias de la sociedad debe ser supervisado cuidadosamente. La sociedad no puede renunciar a la discusión y confrontación democrática de las ideas ni a la pluralidad de opiniones, creencias y valores.

El déficit que El Salvador actual presenta en participación ciudadana no es fortuito, sino que está relacionado intrínsecamente con la estructura social predominante. En consecuencia, su superación no es cuestión de voluntarismos más o menos bien intencionados, sino de transformaciones estructurales radicales. La mayor o menor participación de la ciudadanía en la construcción de su destino es una cuestión de poder, un poder delegado o conquistado en nombre de un democratización solidaria y justa.

San Salvador, 14 de mayo de 1998. 